\title{
EL CABALLERO DEL VERDE GABÁN \\ Y EL CABALLERO DE LOS LEONES: \\ LA PLENITUD DEL ENCUENTRO
}

FRANCISCO VIVAR

The University of Memphis

En la aventurera vida de don Quijote se impone un intersticio, que ocupa el tiempo necesario para que el caballero andante y don Diego Miranda se expresen y se conozcan. En la azarosa vida se cuela la plenitud del encuentro de dos personajes que representan la fidelidad a su propio destino. Como consecuencia, en la presentación de la vocación de don Diego Miranda y en la autoafirmación de don Quijote asistimos a una profunda exploración del ser humano, de lo que es y de lo que puede llegar a ser. De ahí que al analizar este episodio no puedo menos que recordar la opinión de Milan Kundera sobre el género novela: "La novela no examina la realidad sino la existencia. Y la existencia no es lo que ya ha ocurrido, la existencia es el campo de las posibilidades humanas, todo lo que el hombre puede llegar a ser, todo aquello de que es capaz» ${ }^{1}$.

Efectivamente, después del exitoso encuentro de don Quijote con el Caballero de los Espejos, el caballero andante se hallará en su camino con nuevos desafíos, no en forma de batallas que tiene que vencer, sino de personajes de la nobleza o cercanos a ella a los que enfrenta su ideal ${ }^{2}$. El primero de ellos es don Diego Mi-

\footnotetext{
${ }^{1}$ Milan Kundera, El arte de la novela. Barcelona, Tusquest, 1994, p. 54. También en el análisis de este episodio me he dejado llevar por el consejo y la práctica de lector de mi admirado Michel Montaigne cuando nos dice que «en los libros sólo busco deleitarme mediante sano entretenimiento; o si estudio, solo busco con ello el saber que trata del conocimiento de mí mismo y que puede instruirme para bien morir y bien vivir», en Ensayos, vol. II, ed. de Dolores Picazo y Almudena Montojo. Madrid, Cátedra, 1998, p. 98.

2 Muy oportunamente nos recuerda Jean Canavaggio que «a poco de comenzar la Segunda Parte, la nobleza se incorpora con pleno derecho a la ficción, en

$A C$, XXXVI (2004), 165-186
} 
randa y con él Cervantes nos presenta una clase social: la clase intermedia. Los tres capítulos conforman una escena minuciosamente descrita para conocer la vida de don Diego, así como la función social y el ideal de vida de la clase intermedia. El vestido, la casa, el comportamiento y el diálogo de don Diego con don Quijote son una invitación para que el Otro - don Quijote y el lector- lo reconozca y, al mismo tiempo, permiten legitimar la clase social intermedia. De ahí que estos elementos se presentan como la circunstancia, que nos lleva a la vida de don Diego, y como manifestaciones ritualizadas, que permiten la cohesión y la diferenciación de esta clase social.

Por supuesto, además de la presentación de esta clase intermedia, en estos tres capítulos Cervantes confronta el proyecto de vida de don Diego con el ideal de vida de don Quijote, lo que permite al lector examinar y juzgar ambos comportamientos. Es decir, el autor nos sitúa ante dos maneras de comportamiento aparentemente opuestas, desde el contraste nace la $d u d a$ en el lector y, desde ahí, el lector puede enjuiciar cuál de los dos es más 'verdadero'. Una vez llegado a este punto, el lector puede mirarse a sí mismo y a los demás para elegir un comportamiento $\mathrm{u}$ otro; pero también puede encontrar entre ambos comportamientos una armonía. Si utilizáramos una analogía con dos términos musicales, diríamos que los dos personajes se presentan primero como dos notas en contrapunto, punctus contra punctus; para que el lector busque el acorde armónico. Claro está, la armonía reconoce primero un dualismo en el comportamiento humano, una polaridad entre idealismo y sentido práctico, aunque el resultado final exija un acuerdo entre las dos voces.

En ningún otro episodio la hermenéutica ha ofrecido resultados tan diferentes como en éste de don Diego Miranda, debido a

\footnotetext{
vez de hacerlo como antes, a través de episodios adventicios. Así es cómo se imponen a la curiosidad del lector tres representaciones emblemáticas de un mundo que conjuga los privilegios del linaje con el prestigio que confiere la riqueza heredada: don Diego Miranda, el Caballero del Verde Gabán, símbolo de una genry que se alza de la mera hidalguía a las capas inferiores de la nobleza de caballeros»; los otros dos eran los Duques y don Antonio Moreno; en "La España del Quijote" recogido en el libro Cervantes, entre vida y creación. Alcalá de Henares, Centro de Estudios Cervantinos, 2000, pp. 85-93; pp. 88-9. También Maxime Chevalier señala como "el discurso del héroe se va diversificando en la Segunda parte, introduciéndose en él, al lado de los universos de ensueño que obsesionan al caballero, un amplio conjunto de problemas muy concretos que obsesionan al hidalgo: la guerra, el duelo, la nobleza, el casamiento, las relaciones entre padres e hijos, los preceptos de la cortesía, las leyes de la ciudad. En esta Segunda parte el discurso sobre la novela retrocede frente al discurso sobre las exigencias morales y la vida social», en "Cinco proposiciones sobre Cervantes», NRFH, 38 (1990), pp. $837-848$, p. 837 .
} 
que la crítica ha buscado con insistencia una posición moral ante la actitud de los dos caballeros y no un cuestionamiento y una posible armonía en esas voces contrapuestas. Don Diego y don Quijote autolegitiman su ideal de vida y ponen en evidencia sus diferencias. De esta manera Cervantes permite al lector profundizar en los valores humanos de ambos, pero no nos ofrece una solución, ni aceptar un modelo para abandonar el otro, sino que nos exige un cuestionamiento y una búsqueda de nuestra existencia. En definitiva, estos capítulos nos ofrecen una historia del comportamiento del ser humano y de sus posibilidades, nos presentan la verdadera dimensión del hombre. La duda y la pregunta que nos plantea el texto, nos exigen, como individuos, una afirmación de nuestra personalidad. En definitiva, ser más humanos: vivir con plenitud, vivir en armonía ${ }^{3}$.

Don Quijote sólo tiene como modelos de vida al guerrero y al santo, son los únicos que él se plantea seguir porque el caballero andante es santo y héroe. Sin embargo, El Cortesano publicado en 1528 o El Enquiridión (1503), dos libros situados en una época de transformación social, ponen en evidencia la decadencia de estas dos figuras: el caballero necesita adaptarse a las exigencias militares y religiosas del mundo moderno. Por lo tanto, el antiguo caballero o se transforma en cortesano y en hombre cristiano o, por el contrario, le será difícil encontrar su lugar social ${ }^{4}$. El individuo aparece en el Renacimiento, y según va pasando el tiempo se hace evidente que los ideales heroicos van a ser sustituidos por la felicidad personal que proporcionan los placeres cotidianos. Como observamos ya claramente a mitad del siglo XIX: el ideal heroico ha sido sustituido por el ideal burgués. Nobert Elias observa la fina sensibilidad de Erasmo, en libros como Colloquia y Civilitate forum, "en todas las cuestiones relativas a la represión

${ }^{3}$ De esta manera coincido con Jean Cannavaggio cuando se pregunta por los propósitos de lo real en la obra y contesta que "primeramente, permitir a don Quijote resucitar la andante caballería, haciéndola surgir de los libros para encarnarlos en lo cotidiano; después, poner de manifiesto la reticencia que lo cotidiano opone al héroe, condenando su proyecto al fracaso", ibid., pp. 85-6, para concluir que la España que presenta el Quijote es «metáfora -o metonimia- de una España ya abolida, la España del Quijote la transciende en un trabajo del texto en el que no se ha dejado de profundizar desde hace cuatrocientos años. Se nos aparece como un lugar fuera de cualquier lugar y del cual cada lector sitúa e identifica las señales, para remodelarlo a merced de sus curiosidades y deseos", ibid., p. 93.

${ }^{4}$ Véase el capítulo $\mathrm{X}$, «El caballero andante», del interesante libro de PAUL ZuMTHOR, La medida del mundo. Madrid, Cátedra, 1993, aquí se nos dice que «en 1528, el Cortesano de Baltasar de Castiglione pasa una página. El antiguo caballero será cortesano o no será nada», p. 205. 
de los impulsos» y al compararlos con las pautas medievales concluye que "los diálogos erasmianos muestran un avance decisivo en la dirección de aquel tipo de represión de los impulsos que posteriormente justificó en el siglo XIX bajo la forma de la moral $»^{5}$.

Don Diego es ya una clara imagen de los nuevos tiempos renacentistas, se sitúa entre el soldado y el santo. El periodo moderno no exige la extremosidad de los comportamientos medievales. Pero también el del Verde Gabán se encuentra entre el rico y el pobre, pertenece a esa clase social situada entre la nobleza de los duques y el "hidalgo escuderil» que representa don Quijote, o entre «el rico» Camacho y el pobre Sancho, él es «medianamente rico» ${ }^{6}$. Así pues, como he afirmado anteriormente, creo que Don Diego se sitúa en el grupo social que José Antonio Maravall ha denominado «la clase intermedia» ${ }^{7}$. La virtud de don Diego es fruto de una estricta disciplina, consiste en la práctica de la moderación, la proporción, el justo medio; y se va formando en oposición a la alta nobleza y a sus excesos. Es verdad que el del Verde Gabán vive en el campo, lo que haría difícil incluirle en este grupo social; sin embargo, como explicaré después, su comportamiento y las aspiraciones que tiene para su hijo coinciden con la estructura de pensamiento de esta clase social. Como el proyecto de vida de don Diego para con su hijo es uno de los núcleos de mi explicación, me detengo en dos situaciones históricas que van a ser pertinentes para comprender sus aspiraciones.

José Antonio Maravall señala que la fase inicial en la formación de una clase media se aprecia ya en el siglo XvI y se va presentando como una alternativa para reemplazar a la nobleza en el servicio del rey y del Estado. Al dudar del servicio que ofrece la nobleza al rey, el objetivo de esta clase media, según Maravall, es ir reemplazándola en los servicios del Estado. Por supuesto, debi-

${ }^{5}$ NORBERT ELIAS, El proceso civilizador. Investigaciones sociogenéticas y psicogenéticas. México, Fondo de Cultura Económica, 1993, p. 210.

${ }^{6}$ Cito por la edición de Francisco Rico, Don Quijote de la Mancha. Barcelona, Crítica, 1998. Recordamos que según Sansón Carrasco los caballeros consideran a don Quijote un «hidalgo escuderil» (II, 2, 643), esta opinión acerca a Alonso Quijano a la descripción que nos daba Antonio de Guevara de los hidalgos: "No es de pasar entre renglones lo que hace un pobre hidalgo cuando va a la villa a mercado. El se viste un largo capuz, se reboza una toca casera, se encasqueta un sombrero viejo, se pone unas espuelas jinetas, se calza los borceguíes del domingo, alquila una borrica a su vecino, vase en ella caballero, lleva los pies metidos en las alforjas, en la mano un palo con que la aguija, y lo mejor de todo es que a los que le topan dice que tiene el caballo enclavado y a los del mercado dice que lo deja en el mesón de la puente arrendado", en Menosprecio de corte y alabanza de aldea, ed. Asunción Rallo. Madrid, Cátedra, 1984, p. 168.

${ }^{7}$ Véase su libro Poder, honor y elites en el siglo XVII, Siglo XXI, Madrid, 1979. 
do a su sentido práctico "la mentalidad de estos grupos intermedios también, sin duda alguna, era poco simpatizante con los ideales caballerescos ${ }^{8}$. También comprobamos la realidad de estas aspiraciones, en los estudios de Bartolomé Bennassar. Este historiador ha señalado la presencia de «la gente media» y el poder de los letrados en los puestos del Estado, hecho que tuvo como consecuencia un aumento muy importante del número de estudiantes. Precisamente, este auge alcanzó su apogeo entre los años 15801620, "ello se explica evidentemente por las salidas profesionales aseguradas a los 'hombres de letras' y constituyó la celebridad de los colegios mayores convertidos en semilleros de altos funcionarios y de prelados» ${ }^{9}$. El hijo de don Diego aspiraría a pertenecer a este grupo de forma plena, si sigue los deseos del padre. Así, el proyecto del padre sería una realidad vivida en la persona del hijo.

Desde estos puntos de partida, es hora ya de mostrar cómo don Diego va a autolegitimar a esta clase intermedia desde la presentación del vestido, la casa, la virtud, la conversación con don Quijote y la actitud hacia su hijo. De esta manera el episodio pone de manifiesto una autoconciencia de clase social reflejada en la estructura del comportamiento de don Diego. Para comprender la presentación de don Diego son muy oportunas estas palabras de Michel de Montaigne: «Por este motivo dicen los sabios que para juzgar bien a fondo a un hombre, es menester principalmente controlar sus acciones comunes y sorprenderle en su quehacer diario» ${ }^{10}$. Ahí acude, precisamente, Cervantes a "las acciones comunes» y al "quehacer diario» para que el Otro lo reconozca. Es la novedad del episodio que por este camino nos va acercando a la novela del siglo XIX por la información que nos ofrece del personaje, ya que nos va a contar con detalle no sólo de su apariencia física, de su manera de hablar y actuar; sino también nos proporciona información del pasado - la casa con su escudo de armas - como hijo de caballero rural para desde ahí comprender las causas de su comportamiento presente. Ahora bien, como he señalado anteriormente, al entrar en este episodio no nos encontramos sólo con un enfrentamiento entre los ideales de la clase media y los de don Quijote, sino que nos situamos también en un contexto de referencias tácitas respecto a Camacho «el rico» y a los duques que vendrán a continuación ${ }^{11}$.

\footnotetext{
${ }^{8}$ Ibid., p. 285.

9 Bartolomé Bennassar, La España del Siglo de Oro, Barcelona, Crítica, 2001, p. 45.

${ }^{10}$ Ibid., p. 459.

11 Jorge Luis Borges señaló que el Quijote «es la primera y la más íntima de las novelas de caracteres y el postrimero y el mejor de los libros de caballería»
} 
Cuando el hidalgo Quijada, Quesada o Quijana decide convertirse en Don Quijote de la Mancha uno de los actos importantes en la transformación es vestir una armadura de caballero andante. También en la Edad Media la nobleza al cumplir su función de clase caballeresca tiene que adaptar su cuerpo de acuerdo con el ideal social que se dispone a cumplir. Para ello el caballo y las armas le llevan al combate, y el vestido, con su forma y color, le ofrece una identificación ante el Otro y con su grupo social. El vestido otorga a la persona una forma y una función social, lo que vemos por fuera se corresponde con lo que la persona siente por dentro, reflejo de un carácter y de una identidad social ${ }^{12}$. De aquí que no nos extraña que lo primero que nos presenta el narrador en el capítulo XVI es el vestido que va a explicar un carácter y a representar una clase social. El vestido se presenta ante la mirada del Otro, don Quijote, Sancho y el lector, para que el personaje sea reconocido y para que tenga una existencia dentro de un grupo social. El narrador nos presenta a ese hombre que encuentra don Quijote en su camino después de vencer al Caballero de los Espejos de esta manera:

En estas razones estaban, cuando los alcanzó un hombre que detrás dellos por el mesmo camino venía sobre una muy hermosa yegua tordilla, vestido un gabán de paño fino verde, jironado de terciopelo leonado, con una montera del mismo terciopelo; el aderezo de la yegua era de campo y de la jineta, asimismo de morado y verde; traía un alfanje morisco pendiente de un ancho tahalí de verde y oro, y los bordeguíes eran de la labor del tahalí; las espuelas no eran doradas, sino dadas con un barniz verde, tan tersas y brunidas que, por hacer labor con todo el vestido, parecía mejor que si fuera de oro puro (II, 16, 751).

El narrador nos presenta con minucioso detalle el vestido, resaltando aquellos elementos que muestran el cuidado que tiene el personaje al elegir las partes de su vestuario: cada parte tiene que

(Obras completas. IV. Barcelona, Emecé, 1996), p. 45; me atrevo a decir que quizás sea en este episodio donde más claramente veamos esta novela de caracteres. También EDWARD C. RILEY observó la novedad de estos tres capítulos: "con don Diego, Cervantes inaugura un camino que conduciría directamente a la novela decimonónica» (Introducción al Quijote. Barcelona, Crítica, 1989), p. 181.

12 Paul ZumThor señala que a mediados del siglo IX «el hombre noble trata de modelar su cuerpo de acuerdo con un ideal a un tiempo deportivo (a caballo y en combate) y estético (esbeltez y gran estatura), al mismo tiempo que promueve hasta la condición de emblemas el material, las formas y colores de la vestimenta, su envoltura espacial más cercana. Esta semantización de la apariencia corporal se encuentra englobada en una concepción totalizadora del ser humano", en op. cit., p. 39. Así, por ejemplo, en el Persiles se nos dice «a este punto llegaba el bárbaro español, que este título le daba su traje», cito según la edición de JUAN BAUTISTA Avalle-Arce, Los trabajos de Persiles y Segismunda. Madrid, Castalia, p. 78. 
"hacer labor con todo el vestido». Como nos han mostrado Gerald L. Gingras, Monique Joly y Augustin Redondo, el traje y el caballo se corresponden con los usados por el grupo social de los hidalgos rurales ricos en la época para el paseo ${ }^{13}$. Si esto es así lo que habría que destacar son el cuidado y la atención que el personaje presta al detalle como manifestación de un orden que prefigura el ideal burgués ${ }^{14}$. De nuevo, para apreciar la diferencia podríamos recordar a la duquesa vestida de verde. El énfasis en el orden y en el cuidado del vestido lo encontraremos en la casa, en la comida y en los objetivos vitales. Don Diego moldea su cuerpo de acuerdo con el ideal de vida basado en el orden y la moderación. De esta manera, entramos en la escena desde la presentación exterior del personaje, para ir después viendo como otros elementos y actos se van ajustando a esa primera presentación. En efecto, el vestido adquiere una significación profunda al expresar la conciencia de un grupo social, la clase media; pero, también, con el detalle del vestido se va acomodando la oposición esencia-apariencia, dentro-fuera, porque lo que vemos por fuera se corresponde con lo que el personaje siente por dentro. De ahí que a continuación se nos diga que «miraba don Quijote al de lo verde, pareciéndole hombre de chapa» (II, 16, 751-2), y después el narrador asegure que «en el traje y apostura daba a entender ser hombre de buenas prendas» (II, 16, 752). Por el contrario, el caminante don Diego se admira "de la apostura y rostro de don Quijote» (II, 16, 751). Primer contraste. Ahora bien, todavía estamos situados en el terreno de las apariencias y de las impresio-

${ }^{13}$ Véanse los artículos de Gerard L. Gingras, «Diego Miranda, 'Bufón' or Spanish Gentleman", Cervantes, 5 (1985), pp. 129-140; MoNIQuE JolY, "Sémiologie de vetement et inerprètation du texte», Revista Canadiense de Estudios Hispánicos, 2 (1977), pp. 54-64; Augustin REDONDo en «El personaje del Caballero del Verde Gabán", recogido en Otra manera de leer el Quijote. Madrid, Castalia, 1998, pp. 265-289.

${ }^{14}$ En palabras de EdwaRd C. RILEY: «el Caballero del Verde Gabán parece efectivamente un ejemplo precoz del bon bourgeois, prudente, un poco filisteo y, como sugiere su discurso autointroductorio, algo satisfecho de su moderación erasmista y de su epicureísmo complaciente» (Introducción, p. 179). Observación que también hizo F. MÁRQUEZ VILLANUEVA al señalar que "el escalpelo cervantino hurga en lo más hondo de una moral anticipadamente burguesa para aislar en su nervio la ya conocida ecuación entre totum bonum y commodum, quintaesencia para el ethos erasmista», véase el capítulo "El Caballero del Verde Gabán y su reino de paradoja», pp. 147-227, en Personajes y temas del Quijote. Madrid, Taurus, 1975, p. 169. Por su parte Augustin Redondo ve en don Diego la representación de «un espíritu libre, que se guía por la discreción, por la razón, y anuncia ya tiempos nuevos, los que han podido personificar asimismo, en la realidad circundante, los mejores representantes del contemporáneo movimiento arbitrista», en op. cit., p. 289. 
nes, los dos caminantes se miran con atención y están preparados para conocerse: cada uno está ávido de ser reconocido por el otro.

El diálogo entre don Diego y don Quijote pone de manifiesto la necesidad de afirmarse de cada personaje, de proclamar lo que se es ante el otro y ante la sociedad. Los dos exhibirán con ostentación los valores de su ideal de vida porque los dos se presentan como fieles a un destino y a una vocación. Llevado, quizás, por el optimismo de su anterior victoria, don Quijote se adelanta al «de lo verde» para afirmar su identidad en su voluntad de recuperar los ideales de la caballería andante: «soy caballero» y «quise resucitar la ya muerta andante caballería» (II, 16, 752). Después destaca los esfuerzos que exige su profesión y, también, los triunfos conseguidos; con esta información, concluye don Quijote, no podrá admirarse don Diego de su aspecto exterior, pues ya sabe "quién soy y la profesión que hago» (II, 16, 753). En esta afirmación de identidad don Quijote expone su ideal y manifiesta su destino teniendo plena conciencia de que está fuera del tiempo presente y de que su estado físico, «la amarillez de mi rostro, ni mi atenuada flaqueza» (II, 16, 753), no se ajusta con la esforzada profesión que desempeña. Sin embargo, él lo compensa con la voluntad de creer y de ser. Las palabras del caballero andante representan una memoria y un proyecto de vida que entra en conflicto con el presente real antagónico. Don Quijote sabe que en este camino va solo, como el santo y como el héroe, pero aun así necesita ser reconocido ${ }^{15}$. Aunque no le acompañe y aunque pueda que no le comprenda, don Diego necesita conocer sus valores: esfuerzo, generosidad, ayuda a los débiles, búsqueda del bien y deseo de fama. Esta es la pretendida labor de don Quijote. Una vez conocida su función, y a pesar de la ironía que suponen tan grandes empeños para la «amarillez» y «flaqueza» del caballero de la Triste Figura, don Diego y el lector pueden tener en cuenta y profundizar en estos elevados valores humanos, siempre en peligro de desaparición o de ser reducidos a meras palabras, hasta

${ }^{15}$ Como muy bien observó EDWARD C. RILEY «su sentido del esfuerzo heroico incluye la conciencia de ser lo que las acciones hacen de él («hijo de sus obras») y de ser el determinante de sus acciones («artifice de su ventura»). Su personalidad, por tanto, actúa como fuerza formadora que a su vez es formada.[...] Don Quijote siempre es consciente del proceso, tanto si en un momento está diciendo: «Yo soy aquel para quien están guardados los peligros, las hazañas grandes, los valerosos fechos" (I, 20, p. 219), como si dice: "Yo hasta agora no sé lo que conquisto a fuerza de mis trabajos» (II, 58, p. 1097, p. 41); en el capítulo "Quién es quién en el Quijote. Una aproximación al problema de la identidad», del libro La rara invención. Estudios sobre Cervantes y su posteridad literaria. Barcelona, Crítica, 2001, p. 41. 
llegar a ser olvidados del actuar. En esta presentación vemos también la victoria parcial en las derrotas de nuestro héroe que señaló Georg Lukács con estas palabras:

Don Quixote is the first great battle of interiority against the prosaic vulgarity of outward life, and the only battle in which interiority succeeded, not only to emerge unblemished from the fray, but even to transmit some of the radiance of its triumphant, though admittedly selfironising, poetry to its victorious opponent ${ }^{16}$.

La contestación de don Diego pone en evidencia el peso del tiempo en que viven los personajes, la actualidad que se impone como inevitable: "¿Cómo y es posible que hay hoy caballeros andantes en el mundo...? No me puedo persuadir que haya hoy quien favorezca viudas,...» (II, 16, 753). El peso práctico del hoy. La presencia y el contraste de los tiempos están muy claros en todo el episodio. La glosa escrita por el hijo de don Diego insiste en estos mismos temas: «Si mi fue tornase a es,/ sin esperar más será [...]. Cosas imposibles pido,/ pues volver el tiempo a ser/ después que una vez ha sido,/ no hay en la tierra poder/ que a tanto se haya estendido" (II, 18, 778). El pasado no puede volver, ni se puede vivir en el pasado, porque hay un presente y un futuro. Ahora bien, esta conciencia del tiempo la tiene don Quijote. El sólo quiere «recuperar» los valores antiguos para que tengan un sentido en el presente y en el futuro, como nos va a mostrar a lo largo del episodio. Para don Quijote los suyos son los valores más dignos que podemos encontrar en el espíritu humano, y como en su tiempo están olvidados es importante recordarlos.

El del Verde Gabán en su primera afirmación de identidad va a presentarse, sobre todo, como un hombre virtuoso. Primero señala su posición social: es un hidalgo «medianamente rico», lo que le permite llevar un don: don Diego Miranda. Después nos habla de su situación familiar y, a continuación, de sus hábitos y costumbres: le gusta la caza y la pesca, lee de vez en cuando, tiene amigos. Para terminar con sus valores morales: "no murmura»,

${ }^{16}$ The Theory of the Novel, Cambridge, The MIT Press, 1999, p. 104. Es oportuno recordar las palabras que unas líneas antes ofrece Georg Lukács sobre el comienzo de la novela con estas palabras: "Thus the first great novel of world literatura stands at the beginning of the time when the Christian God began to forsake the world; when man became lonely and could find meaning and substance only in his own soul, whose home was nowhere», ibid., p.103, y unas líneas después: "Cervantes lived in the period of the last, great and desperate mysticism, the period of a fanatical attempt to renew the dying religion from within; a period of a new view of the world rising up in mystical forms; the last period of truly lived life by already disoriented tentative, sophisticated, occult aspirations", p. 104. 
va a misa, practica la caridad, es devoto. Las palabras de don Diego, que ensalzan su vida mediocritas y virtuosa, moderada y ordenada, situada en el justo medio, intentan autolegitimar su situación social de capa media ante los demás grupos sociales, y expresan un nuevo contenido existencial producto de una situación histórica. Y es que, insisto, después de don Diego nos encontramos con Camacho "el rico» y los duques. El del Verde Gabán representa un tipo humano que personifica la moderación y la virtud frente a la extravaganza del rico y a la ociosidad de la nobleza. Pues, como afirma J. A. Maravall, «este tópico de la mediania» fue recogido por los economistas para transformarlo en «una fórmula social» que fuera formando «una estructura de capas medias, sobre las cuales habría de buscar su apoyo la organización del poder político, ayudando por su parte a que de ella salieran los selectos que se incorporarían a la minoría gobernante» ${ }^{17}$. A través de la virtud la clase media se distinguía de las capas altas de la sociedad; pero la virtud debía ir acompañada de la educación. Este mismo pensamiento se comprueba en el Persiles cuando Rutilio responde a Clodio: "Yo no soy tan letrado como tú; pero bien alcanzo que los que nacen de padres humildes, si no los ayuda demasiadamente el cielo, ellos por sí solos pocas veces se levantan adonde sean señalados con el dedo, si la virtud no les da la mano»18. Don Diego representa la aspiración de una clase media ascendente desde los puestos del Estado. Por esta razón, siguiendo el diseño del padre, el hijo tiene que ir a la Universidad para ser letrado. Todos los actos de don Diego son calculados y están dirigidos a un objetivo, pues como señalaba Montaigne «al que no ha dirigido el conjunto de su vida a un determinado objetivo, le es imposible disponer los actos individuales. Es imposible colocar las piezas para aquel que no tiene la forma del conjunto en la cabeza» ${ }^{19}$. Don Diego tiene todo ordenado de acuerdo a un objetivo vital legítimo, distinto al que tiene don Quijote o al que veremos en el comportamiento de Camacho o de los duques. El contenido existencial que expresan las palabras de don Diego está basado en la racionalización de la existencia, no muy lejos del espíritu capitalista explicado por Max Weber con estas palabras:

Parece, por tanto, que el desarrollo del 'espíritu capitalista' se podría entender sencillamente como un fenómeno parcial dentro del desarrollo global del racionalismo y que debería deducirse de la posición

\footnotetext{
${ }^{17}$ Op. cit., p. 272

18 Op. cit., p. 184

${ }^{19}$ Op. cit., p. 16.
} 
de los principios racionalistas respecto a los problemas últimos de la vida ${ }^{20}$.

Fiel a su autoconciencia de clase mediana don Diego abandona la autosatisfacción personal para señalar el problema que tiene con su hijo: "Yo señor don Quijote - respondió el hidalgotengo un hijo, que, a no tenerle quizá me juzgara por más dichoso de lo que soy, y no porque él sea malo, sino porque no es tan bueno como yo quisiera» (II, 16, 755, énfasis mío). Palabras que nos parecen consecuentes con la autolegitimación que anteriormente ha hecho de su grupo, puesto que expresan la conciencia de su proyecto, que es reforzado cuando señala don Diego que su hijo estudia en Salamanca; pero en contra de lo que él quería:

halléle tan embebido en la de la poesía (si es que se puede llamar ciencia), que no es posible hacerle arrostrar la de las leyes, que yo quisiera que estudiara, ni de la reina de todas, la teología. Quisiera yo que fuera corona de su linaje, pues vivimos en siglos donde nuestros reyes premian altamente las virtuosas y buenas letras, porque letras sin virtud son perlas en el mudalar (II, 16, 756).

El hijo de don Diego si siguiera la estructura de comportamiento del padre se convertiría en un servidor del Estado o de la Iglesia, de esta manera ascendería socialmente al recibir los beneficios de la Corte. En la profesión que don Diego quiere para su hijo expresa la conciencia de su destino como clase social o de un grupo «que podía proporcionar una nueva élite» para reemplazar a la nobleza, como explica Maravall ${ }^{21}$. Esta necesidad de las letras ya la había advertido Erasmo con estas palabras: «entonces, tengan en cuenta que no sólo la tierra da con que vivir, sino también la preparación intelectual que es la mejor fortuna, pues se-

${ }^{20}$ MAX WEBER, La ética protestante y el 'espiritu' del capitalismo. Traducción y nota preliminar de Joaquín Abellán. Madrid, Alianza, 2001, p. 83.

${ }^{21} \mathrm{Op}$. cit., p. 257. Los actos y palabras de don Diego se entienden dentro del desafío que venía desarrollando la clase media, pues como señala MARAVALL «la formación de una clase media en ascensión por varios conductos hacia el poder y la de un mercado nacional, son dos procesos que se pueden reconocer en fase inicial en el siglo XVI; pero que la recesión represiva y restauradora de fórmulas mediavalizantes que conoce el Barroco interrumpe en su marcha», p. 301. También era importante el debate de la "nobleza de la letras" que explica Bartolomé Bennassar de esta manera: "¿Podían las letras ejercer una función ennoblecedora, merced al saber que ofrecían, los títulos que conferían, los cargos importantes que permitían desempeñar? La respuesta de la Historia fue reservada: el ennoblecimiento estuvo limitado a los doctores de las grandes universidades y a los licenciados que detentaron realmente un cargo elevado; se trataba, por añadidura, de una nobleza vitalicia, no transmisible a los herederos», op. cit., p. 47. 
gún dice un proverbio más vale saber que haber, que el haber no compra ciencia, y el saber nunca se acaba» ${ }^{22}$.

Don Diego está aferrado a la realidad, vive en el presente inmediato y tiene un proyecto que le da fuerzas para el futuro. Aunque el de lo Verde no ataca directamente los valores de la nobleza, sí se enfrenta a su comportamiento ocioso al ponerse en relación de comparación. Don Diego vive del cuidado de sus tierras en el pueblo, pero no quiere ese mismo destino para su hijo, quiere que su hijo trabaje para la Corte o la Iglesia para así ascender socialmente. Este es su proyecto. Aunque no forme parte de la sociedad cortesana, sí recibirá los beneficios de la Corte para ir ascendiendo socialmente y ejercer una influencia directa en el Estado que permita romper la estructura estamental de la nobleza basada en el privilegio; ya que ahora viven «en siglo donde nuestros reyes premian las virtuosas y buenas letras».

Sin embargo, para don Quijote lo importante son los ideales heroicos. Él vive atrapado en su memoria y en la voluntad que tiene de "recuperar» los valores de la caballería. Si don Diego vive en el presente porque no ve otra posibilidad de existencia sino acomodarse a la circunstancia, don Quijote no se doblega al presente y ajusta su destino de acuerdo con los ideales de la caballería. Aunque viva en una "edad de hierro» cree que con su voluntad de héroe podrá instaurar los ideales de una «edad de oro». Prefiere lo ideal a lo real. Este es su proyecto: acomodar la realidad a sus ideales e influenciar la realidad para transformarla. La manera más evidente de mostrar su proyecto a los demás es a través de la aventura. Esto es así, porque como señala Ortega y Gasset «la aventura quiebra como un cristal la opresora insistente realidad. Es lo imprevisto, lo impensado, lo nuevo. Cada aventura es un nuevo nacer del mundo, un proceso único» ${ }^{23}$. El héroe busca la aventura, la gente común la vida ordenada del presente. La aventura frente al mundo repetitivo de los hechos humanos.

Al comenzar el capítulo XVII don Quijote cree y piensa «que todo lo que le sucediese habían de ser aventuras y más aventuras» (II, 760). Este es su proyecto: transcender lo cotidiano a través de la aventura, sea ésta necesaria o inútil. Efectivamente, en

${ }^{22}$ Educación del príncipe cristiano. (Tecnos, Madrid, 1996), p. 133. Los padres de Carriazo y Avendaño en La ilustre fregona se comportan de manera semejante: "los padres dieron documentos a sus hijos de lo que habían de hacer y de cómo se habían de gobernar para salir aprovechados en la virtud y en las ciencias, que es el fruto que todo estudiante deber pretender sacar de sus trabajos y vigilias, principalmente los bien nacidos»; Novelas ejemplares, II, ed. de Harry Sieber. Madrid, Cátedra, 1994, p. 144.

${ }^{23}$ Meditaciones del Quijote. Ideas sobre la novela. Madrid, Austral, 1976, p. 122. 
las palabras de autopresentación de don Diego el caballero andante ha percibido la reducción de su ideal caballeresco, que el del Verde Gabán ha convertido en una filosofía de andar por casa. La vida apacible y tranquila de la cotidianidad es muy limitada para don Quijote porque los hechos se repiten y desaparece la aventura. Por el contrario, él necesita vivir la epopeya de los héroes que convierten lo cotidiano en aventura por un acto de voluntad. Al intentar don Diego desanimar a don Quijote para que no se enfrente a los leones, hecho que el del Verde Gabán considera una locura, nos encontramos con estas palabras del caballero andante: «Váyase vuestra merced, señor hidalgo - respondió don Quijote-, a entender con su perdigón manso y con su hurón atrevido, y deje a cada uno hacer su oficio. Este es el mío...» (II, 17, 763). Y el narrador dice bien claro que "él sabía lo que hacía» y que "él entendía que se engañaba» (II, 17, 764). Pero he aquí que, en consecuencia nuestro héroe sigue adelante porque, como señala Ortega, "ser héroe consiste en ser uno, uno mismo" y su vida "es una perpetua resistencia a lo habitual y consueto ${ }^{24}$. Y mientras don Diego le califica de «loco» - «no le pareció cordura tomarse con un loco, que ya se lo había parecido de todo punto don Quijote» (II, 17, 764) - ; el narrador le va a calificar de "valeroso manchego» (II, 17, 766). El narrador no juzga, presenta en igualdad a ambos caballeros para que el lector tenga libertad de juicio.

Los dos personajes tienen que seguir su propio ideal de vida, ser fieles a sus objetivos, que el lector puede sentirlos como opuestos o como complementarios que necesitan armonizarse. Uno se presenta como virtuoso, el otro como valiente, uno vive en la cotidianeidad, el otro en la aventura, uno presenta la gesta de la aventura y el otro la gesta cotidiana. De esta manera, los dos personajes nos van a situar ante la ambigüedad del comportamiento humano, lo que provoca el cuestionamiento en el lector $\mathrm{y}$, posiblemente, la búsqueda del 'acorde armónico'25.

La necesidad de don Quijote de afirmarse en sus valores, el deseo de probar su valentía, la búsqueda de reconocimiento ante

\footnotetext{
${ }^{24}$ Ibid., p. 139.

${ }^{25}$ Coincido con el acercamiento de Charles D. PRESBERg a este encuentro: "The self-conscious narrative of the episodes involving the protagonist and the man in green leads both the reader and Don Diego to engage in a process of selfexamination. [...] For Cervantes seemingly casts those episodes in the form of a dialectical debate between two contrary reading - one 'hard,' the other 'soft,' on both the protagonist and his chivalric ethos», en "Yo sé quien soy': Don Quixote, Don Diego Miranda and the Paradox of Self-Knowledge», Cervantes, 14 (1994), pp. 41-69, p. 46 .
} 
don Diego, la invitación de la superación de lo cotidiano que representa la aventura, son contrariados por la reacción de los leones a los que se enfrenta: «Pero el generoso león, más comedido que arrogante, no haciendo caso de niñerías ni de bravatas, después de haber mirado a una y otra parte, como se ha dicho, volvió las espaldas y enseño sus traseras partes a don Quijote, y con gran flema y remanso se volvió a echar en la jaula» (II, 17, 766) ${ }^{26}$. A don Quijote le responde otra vez la realidad de su tiempo, la aventura se convierte en risa. Como señala Paul Zumthor «a partir de 1550, la idea misma de aventura [...], ya sólo provocará risas. Rabelais ya había creado la palabra aventurier para designar a la peor soldadesca. El caballero andante se convierte, en las fiestas mundanas, en personaje de mascarada ${ }^{27}$. Efectivamente, el león parece indicarnos que el héroe, que don Quijote no tiene un sitio en el mundo moderno. Parece que la aventura de los leones fuera gratuita para todos menos para don Quijote, que la valentía mostrada por el caballero es desperdiciada porque no busca ningún propósito digno, sólo la satisfacción personal. En esta situación límite don Quijote se convierte en el "Caballero de los Leones», en el justo medio don Diego es el «Caballero del Verde Gabán». Don Quijote mantiene la fe en los ideales que representa. Después de contar el leonero «la aventura» y la «burla» que sufre el caballero, el Caballero de los Leones afirma: «Bien podrán los encantadores quitarme la ventura, pero el esfuerzo y el ánimo será imposible» (II, 17, 768). Esta es la virtud de don Quijote: la voluntad. El cree en la aventura, es su proyecto. Es importante mantenerse en la aventura el mayor tiempo posible, no dejarse vencer y desafiar las contrariedades. Su ideal no está perdido.

El Caballero de los Leones, como el del Verde Gabán, se da cuenta que en 1600 la caballería se ha convertido en una mascarada, para mostrarlo enumera brevemente los comportamientos de los caballeros contemporáneos, por esta razón le dice a don Diego: «bien parece un gallardo caballero a los ojos de su rey, en la mitad de una gran plaza, dar una lanzada con felice suceso a un bravo toro; [...] pero sobre todos estos parece mejor un caballero andante...» (II, 17, 769). En estas palabras no contradice a don

${ }^{26}$ AUgustin REDondo señala que el episodio de los leones "no puede ser más burlesco», el león bosteza y le enseña el trasero, op. cit., p. 282. Por su parte, F. MÁRQUEZ VILLANUEVA aprecia que la aventura de los leones "no se trata de una aventura ridícula ni frustrada en ningún sentido, sino de un escrupuloso homenaje al dogma fundamental del código caballeresco, que fundaba el prez no en el vencimiento, sino en la aceptación animosa de la aventura y en el no retroceder», op. cit., p. 181.

${ }^{27}$ Op. cit., p. 205 
Diego y a su ideal de vida, sino a una nobleza que ya no es modelo de comportamiento aristocrático. A don Diego sólo le presenta otro modelo de comportamiento que debe considerar porque también ofrece una visión positiva de la existencia. Él revive un mundo mítico y quiere que los demás reconozcan los valores positivos que representa. De ahí que don Quijote haga inmediatamente una defensa de los valores de la caballería y reafirme su oficio: «Yo, pues, como me cupo en suerte ser uno del número de la andante caballería, [...] conocí ser temeridad esorbitante [acometer a los leones], porque bien sé lo que es valentía»(II, 17, 770). En este momento es muy consciente de sus acciones y, también, del presente donde actúa, aun así quiere transformarlo, influenciar a los demás para que también se cuestionen su comportamiento y su existencia. Don Quijote elige su destino y mejora su existencia por la aventura, animado por un proyecto ofrece una vida que rompe con lo cotidiano. Por supuesto, la aventura de los leones es temeraria y gratuita; pero es su "oficio», el destino del héroe es seguirlo a pesar de las dificultades y riesgos. Ahora bien, en 1600 el acto gratuito de don Quijote merece la burla de los leones y la risa de sus contemporáneos. Sin embargo, ¿se ríe de él don Diego como se reirán después los duques? No, el de lo Verde, posiblemente, reconoce el ánimo y la voluntad de don Quijote. Como muestra de agradecimiento le lleva a su casa para que pase allí unos días, actitud que se corresponde con la virtud de don Diego y, también, con el respeto y la comprensión que siente hacia don Quijote. No le invita como loco para divertirse con sus locuras, sino como «noble huésped» para continuar el diálogo y el conocimiento mutuo, llevado de una actitud completamente diferente a la que mostrarán los duques. Don Diego invita al caballero andante y a su escudero al espacio íntimo de la casa, para que ahí don Quijote conozca a su familia, las costumbres que mantiene, y el patrimonio que posee. En el espacio de la casa conoceremos mejor la identidad de don Diego y la legitimación de su clase social. Después de la aventura de los leones, es en la casa donde se nos muestra «la aventura» de la clase media, ahí nos encontramos con la gesta cotidiana.

Como el vestido, la casa se corresponde con la clase social. Don Quijote al llegar halló «ser la casa de don Diego de Miranda ancha como de aldea; las armas empero, aunque de piedra tosca, encima de la puerta de la calle; la bodega, en el patio; la cueva, en el portal; y muchas tinajas a la redonda, que, por ser del Toboso, le renovaron las memorias de su encantada y transformada Dulcinea» (II, 18, 771). Esto es lo que ve don Quijote: una casa solariega de pueblo con el escudo de armas en la puerta. Sin 
embargo, no se fija tanto en el patrimonio como en unas tinajas que le recuerdan a su señora Dulcinea. El héroe vive en su mundo de ideal, la realidad pasa a su lado sin detenerse en ella. Con este pequeño apunte cómico, el narrador nos lleva a la problemática existencial más importante del caballero: Dulcinea. Como consecuencia, es el narrador el que de nuevo nos va a situar en la descripción de la casa, y lo hace de esta curiosa manera:

\begin{abstract}
Aquí pinta el autor todas las circunstancias de la casa de Don Diego, pintándonos en ella lo que contiene una casa de un caballero labrador y rico; pero al traductor de esta historia le pareció pasar estas y otras semejantes menudencias en silencio, porque no venían bien con el propósito principal de la historia, la cual más tiene su fuerza en la verdad que en las frías digresiones (II, 18, 772).
\end{abstract}

Al entrar en un nuevo escenario hubiera sido normal,. siguiendo las convenciones de la novela, describir la casa de don Diego como ha hecho el supuesto "autor»; sin embargo, «el traductor» elimina esta convención porque la considera una digresión inútil para la verdad de la historia. La descripción no añade nada a la comprensión existencial del personaje, es irrelevante, mera verbosidad; lo que sí es importante es señalar que la casa de don Diego es igual que "una casa de un caballero labrador y rico». Si el narrador se ha detenido en la descripción detallada del traje, ahora no es importante para nuestra información describir una casa que pertenece a un individuo que representa a una clase social, resulta conocido para el lector. Además, de esta manera se refuerza la idea de representación de un grupo social. El lector ve en la casa una identidad social que refleja una forma y un ideal de vida, como antes había visto en el vestido verde y como verá en la comida y en el comportamiento. El «traductor» en su afirmación irónica se reserva el derecho de seleccionar lo que considera esencial para comprender al personaje. El novelista que se acerca a «la verdad de la historia» no tiene que describir todos los elementos, sino sólo los esenciales para que el lector capte al personaje ${ }^{28}$.

$\mathrm{Y}$ como la casa es el espacio de la familia, aquí nos encontraremos con la esposa y el hijo de don Diego. En este espacio inte-

\footnotetext{
${ }^{28}$ ANTHONY CLOSE ha estudiado con atención las distintas caras que ofrece el concepto «verdad de la historia» en el Quijote y concluye que "for Cervantes, the essential point of the concept of 'the truth of the history' is precisely the excellent of his comic fiction, and he opposes that truth to the traditional prejudice, reflected in Guzmán de Alfarache, that Duch fiction is nothing more than pleasant lies and that risible matter is shameful, ugly, coarse, malicious, frivolous, even sinful», en Cervantes and the Comic Mind of his Age. Oxford, Oxford University Press, 2000, p. 328 .
} 
rior se nos muestran las costumbres y los valores que ya había apuntado don Diego en la conversación con don Quijote. La virtud de don Diego se corresponde con la virtud de su esposa, y esta correspondencia viene apuntada por la información que nos da la frase: "que por la venida de tan noble huésped quería la señora doña Cristina mostrar que sabía y podía regalar a los que a su casa llegasen» (II, 18, 773). La disposición y el ordenamiento de la mesa, la comida que se presenta y el comportamiento de los comensales constituyen la prueba del «saber» y el "poder» de la familia Miranda ante los demás. La mesa de don Diego es el reflejo del profundo cambio social, político y cultural que han supuesto las clases medias superiores ${ }^{29}$. Además, esta comida es un acto de comunión que crea amistad entre personas de igual calidad, como son los dos caballeros. El narrador ofrece una información concisa de la primera comida de don Quijote en casa de don Diego. La comida fue «limpia, abundante y sabrosa», dominó un "maravilloso silencio» y, finalmente, concluye que todo discurrió "como don Diego había dicho en el camino" (II, 18, 776). La mesa es un reflejo de un ideal de vida que tiene unos comportamientos y unos objetivos muy claros que permiten diferenciar socialmente a este grupo. La mesa y la comida cohesiona y diferencia a don Diego de Camacho y los duques ${ }^{30}$. Ahora se destaca la limpieza, la abundancia y el sabor, pero también el silencio. Es un comportamiento virtuoso. Pero como se nos ha dicho de doña Cristina, son comportamientos que esta clase social ha aprendido para autolegitimar su situación y su aspiración social. Adquiere así, la información que tenemos de la comida como la del vestido y la casa una significación profunda, esencial para comprender la existencia regularizada de este grupo social: la clase mediana. La casa prefigura lo que será en el siglo XIX el interior burgués, lo mismo que la comida prefigura el orden y la virtud burgueses. Sin embargo, en esta ritualización de actos y gestos don Quijote y el lector perciben que "todas las cosas diarias se hacen a la misma hora» y que, además, todo se hace «como don Diego había dicho»,

${ }^{29}$ El libro de Norbert Elias, El proceso civilizador, pone de manifiesto esta afirmación a través del estudio de procesos históricos concretos que muestran las interrelaciones entre los cambios en la constitución de la sociedad y los cambios en la constitución del comportamiento, así como de los hábitos psíquicos. De este libro véase en el capítulo segundo el apartado III «El problema del cambio del comportamiento en el Renacimiento» y el apartado IV "La compostura en la mesa», pp. 115-170.

${ }^{30}$ En las bodas de Camacho la comida es desproporcionada en la abundancia como una muestra de la ostentación del rico, como explico en mi artículo, "Camacho y la sociedad del espectáculo", Cervantes, 22.1 (2002), pp. 82-109. Por otra parte, los duques usan la comida para reírse del apetito de Sancho. 
según nos advertía Azorín ${ }^{31}$. Para un caballero como don Quijote que prefiere lo ideal sobre lo real y para un lector moderno que conoce muy bien la atonía de la vida rutinaria que conllevan las formas de comportamiento burgueses, el comportamiento de don Diego puede ser cuestionado. El del Verde Gabán ha elegido los placeres cotidianos que le proporcionan una vida regularizada, acompañada de las virtudes ordinarias; mientras que don Quijote por el camino de la aventura vive la exaltación de lo cotidiano que le exige virtudes heroicas. Ambos comportamientos nos sitúan ante una problemática vital, pero antes de entrar en ella, sigamos, por unos momentos, con los personajes en la casa.

En la casa de don Diego es el hijo de éste, don Lorenzo el que tendrá que reconocer al caballero manchego. De nuevo don Quijote se muestra ávido de reconocimiento ante el otro. Lo primero que hace es contar a don Lorenzo qué es la caballería andante, la ciencia que la compone y el comportamiento que exige. Al terminar don Quijote, don Lorenzo le responde: "dudo que haya habido, ni que los hay ahora, caballeros andantes, y adornados de virtudes tantas» (II, 18, 775). Don Lorenzo reconoce la alta calidad y exigencia de las virtudes que expone don Quijote, pero duda que sea posible alcanzarlas y vivirlas, ponerlas en práctica, ya fuera en el pasado o en el presente. A esta duda responde don Quijote: «lo que pienso hacer es rogar al cielo le saque dél [error] y le dé a entender cuán provechosos y cuán necesarios fueron al mundo los caballeros andantes en los pasados siglos, y cuán útiles fueran en el presente si se usaran; pero triunfan ahora, por pecados de las gentes, la pereza, la ociosidad, la gula y el regalo" (II, 18, 775). De nuevo, don Quijote se da cuenta que vive en otros tiempos; pero ve la necesidad de introducir dentro del presente el ideal caballeresco para superar la situación social de pereza y ociosidad, y a la vez, para dar legitimidad a su proyecto vital. Es de esto de lo que quiere convencer don Quijote a don Lorenzo, a su padre y al lector, ya que ha introducido una nueva forma de comportamiento dentro de la realidad. La memoria del pasado continúa en el presente, este es el proyecto de don Quijote, cree en una continuidad con un pasado que no se interrumpe. El problema está en que las estructuras sociales no admiten esos valores caballerescos porque han cambiado los tiempos. Sin embargo, frente a la crisis de valores que representan la pereza o la ociosidad del presente, sí serían necesarios los valores del pasado. Es la expresión de la nostalgia y la resistencia a que desaparezcan. En este dilema nos sitúa don Quijote. Me atrevo a decir que de todos los episodios del

${ }^{31}$ Azorín, Lecturas españolas. Madrid, Austral, 1964, p. 44. 
Quijote, es precisamente en éste donde se aprecia con más claridad e intensidad la voluntad de ser del caballero andante. Don Quijote sabe que vive en una edad de hierro que no se corresponde con los valores caballerescos, pero quiere afirmar sus valores caballerescos para mostrar su función en el presente.

Después de cuatro días en casa de don Diego, don Quijote «se quería ir a cumplir con su oficio, buscando las aventuras»(II, 18, 780). De nuevo esta voluntad de marcharse a la búsqueda de aventura, a pesar de estar «regaladísimo» en la casa, expresa la afirmación del héroe que elige su destino y, libre de todo condicionamiento -histórico y social-, es dueño de su existencia. El héroe manchego es consciente de que su ideal puede ser irrealizable, de que sus aventuras pueden convertirse en "desventuras»; pero es su deseo y a él se entrega con toda voluntad como nos dice el narrador: "sus desventuradas aventuras, que las tenía por fin y blanco de sus deseos»(II, 18, 781). En la búsqueda de la aventura, don Quijote va sólo, pero alegre: «Llegóse, en fin, el día de su partida, tan alegre para don Quijote, como triste y aciago para Sancho Panza, que se hallaba muy bien con la abundancia de la casa de don Diego» (II, 18, 780). El espíritu sanchesco gusta de la vida regalada, el ideal es costoso, exige esfuerzo y sufrimiento. Sólo el héroe y el santo aceptan el reto. Y así es como caballero y escudero salen del espacio domesticado de la casa y entran, de nuevo, en el espacio indeterminado de la aventura.

Como sabemos, con el Renacimiento se va afirmando una mentalidad burguesa que se impone en los siglos XVIII y XIX ${ }^{32}$. Don Diego pone en evidencia que el soldado y el santo entran en decadencia por la extremosidad de las exigencias del comportamiento; él participa de la santidad como hombre cristiano y de la vida militar al llevar una espada. Pero no elige estas vidas como dedicación completa, porque llevan a la inoperancia y a la guerra constante. El prefiere los placeres diarios que le garantizan una vida regularizada por la costumbre, a ellos añade el interés manifestado en el control de sus negocios -el cultivo de la tierra- y el futuro de su hijo. Por supuesto, don Quijote ve en don Diego la constricción de lo humano, la reducción del ideal convertido ahora en unos valores acomodaticios. Él afirma su voluntad de ser héroe, su causa, aunque pueda llegar a ser una causa perdida. Por el contrario, la costumbre y la rutina ofrecen a don Diego la quietud del espíritu, la posibilidad de sobrevivir sin el sobresalto conti-

32 PASCAL BRUCKNER en La euforia perpetua. Sobre el deber de ser feliz. Barcelona, Tusquest, 2000, nos ofrece en las páginas 130-136 unas ideas muy sugerentes sobre la mentalidad y el comportamiento burgués que han sido de gran ayuda en la reflexión que ofrezco a continuación. 
nuo: la tranquilidad, las alegrías simples ${ }^{33}$. La aventura, situada en la historia del siglo XVII, se pierde en acciones gratuitas y sobresaltos que pueden llevar al individuo aspirante a héroe a la aniquilación o al desequilibrio. La aventura de los leones es gratuita para todos los que la presencian, menos para don Quijote. La valentía desperdiciada no busca ningún propósito digno, sino la satisfacción personal y una fama inútil.

Don Quijote vive en una situación límite y en ese extremo es el Caballero de los Leones. Don Diego vive en el justo medio, es el Caballero del Verde Gabán. Uno puede llevar al heroísmo o a la autodestrucción en la aventura, el otro a la satisfacción personal de los placeres cotidianos o al aburrimiento de la repetición. Heroísmo y mediocridad, ideal y cotidianeidad, peligro y satisfacción. Al estar situados uno junto al otro, como dos notas musicales en punctus contra punctus, al realizar los personajes una autolegitimación de su vida y objetivos, al ser los dos fieles a su vocación, al hundirse los dos en la experiencia de conocer al otro, Cervantes nos enfrenta a un cuestionamiento esencial en la existencia humana: la ambigüedad del comportamiento humano. Si no entendemos el encuentro como un cuestionamiento corremos el riesgo de quedarnos en los aspectos parciales del comportamiento y de inclinarnos por un personaje en detrimento del otro $^{34}$. Don Diego no es la contrafigura o la imagen invertida de don Quijote, ni tampoco lo que don Quijote hubiera podido ser o hubiera querido ser. No está detrás de don Diego la figura de Lope de Vega o la proyección de Cervantes en este personaje ${ }^{35}$. No, el del Verde

\footnotetext{
${ }^{33}$ Recordamos las palabras de MONTAIGNE al confesarnos: «Toda la gloria que pretendo de mi vida es haberla vivido tranquilo: tranquilo, no según Metradoro o Arcesilao o Aristipo, sino según yo mismon, en op. cit., p. 365.

${ }^{34}$ Es oportuno recordar las palabras de ORTEGA Y GASSET: "Unos, con encantadora previsión, nos proponen que no seamos Quijotes; y otros, según la moda más reciente, nos invitan a una existencia absurda, llena de ademanes congestionados. Para unos y para otros, por lo visto, Cervantes no ha existido. Pues a poner nuestro ánimo más allá de ese dualismo, vino sobre la tierra Cervantes", en $o p$. cit., p.38. O las palabras de MILAN KUNDERA cuando afirma que la novela es imagen y modelo de la Edad Moderna lo que nos exige como lectores «comprender con Cervantes el mundo como ambigüedad, tener que afrontar, no una única verdad absoluta, sino un montón de verdades relativas que se contradicen (verdades incorporadas a los egos imaginario llamados personajes), poseer como única certeza la sabiduría de lo incierto, exige una fuerza igualmente notable», en op. cit., p. 17.

35 Helena Percas de Ponseti veía en el personaje de don Diego una parodia de Lope de Vega y consideraba que «en el auto-elogio de don Diego hay otros detalles que encajarían por alusión paródica a Lope de Vega», en Cervantes y su concepto del arte. Madrid, Gredos, 1975, p. 358. Por su parte, AlBerto SÁNCHEZ señalaba que «tal vez se deleitó morosamente al proyectar en un personaje lo que él mismo [Cervantes] quiso ser y no fue. Vivir una medianía dorada, fugaz anhelo
} 
Gabán personifica los valores de la clase mediana, situado en la realidad de la vida y de los hechos cotidianos, en su deambular la casualidad le lleva al encuentro con don Quijote, situado en el ideal de la aventura, fuera de la realidad y del tiempo pero defendiendo valores tan importantes como la libertad o la justicia. Desde aquí, uno junto al otro, y no uno frente al otro, el episodio nos lleva a la verdadera dimensión del hombre y nos exige buscar y razonar para moldear nuestra vida y ser más humanos. Nos sitúa en la tensión de la pregunta que constantemente se ha hecho el hombre: cómo introducir la aventura en la atonía de nuestra vida diaria, es decir, cómo armonizar los dos comportamientos, cómo buscar el acorde armónico. Por supuesto, es aquí también donde encontramos al autor, Cervantes, explorándose a sí mismo, exponiéndonos su «memoria» de poeta y de soldado, pero también de su vida en Esquivias y de sus comisiones andaluzas, su pensamiento $\mathrm{y}$ su experiencia vital ${ }^{36}$.

El episodio nos presenta los dos comportamientos, nos ofrece (como una revelación) lo que es el hombre, lo que le ha acompañado en su historia desde los comienzos y, como consecuencia, las posibilidades del ser. Esta dualidad del comportamiento humano y la necesidad de encontrar un acuerdo, una armonía, provocan la pregunta que encontramos en estos versos de Jaime Gil de Biedma:

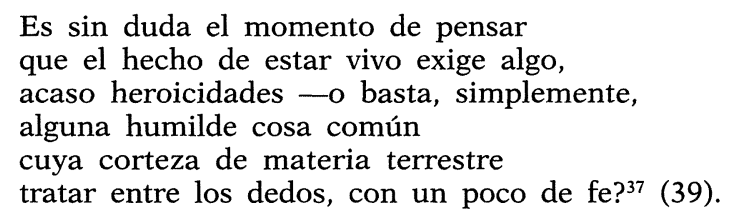

de un genio maltratado por la vida», en «El Caballero del Verde Gabán», Anales Cervantinos, 9 (1961-2), pp. 169-201, p. 201.

36 A la manera en que lo encuentra Borges en las Novelas ejemplares: "Cervantes lo compuso para distraer con ficciones las primeras melancolías de su vejez; nosotros lo buscamos para vislumbrar en sus fábulas los rasgos del viejo Cervantes. No nos conmueven Mahamut o la Gitanilla; nos conmueve Cervantes imaginándolos» (Obras completas, IV. Barcelona, Emecé, 1996), p. 47. O en la manera en que JOSÉ SARAMAGO explica la presencia del autor en la novela: "Una ficción no está formada solamente por personajes, conflictos, situaciones, lances, peripecias, sorpresas, efectos de estilo, juegos malabares, exhibiciones gimnásticas de técnicas de narración, una ficción (como toda obra de arte) es, sobre todo, la expresión ambiciosa de una parcela identificada de la humanidad, es decir, de su autor. [...] Tal y como lo entiendo, la novela es una máscara que esconde y al mismo tiempo revela los trazos del novelista" (Cuadernos de Lanzarote II (19961997). Madrid, Alfaguara, 2001), p. 203.

37 JAIME GIL DE BIEDMA, Las personas del verbo. Barcelona, Seix Barral, 1997, p. 39. 
La pregunta del poeta sobre la gesta cotidiana ha sido constante porque resume la historia de nuestro comportamiento, tal y como lo encontramos en don Quijote y don Diego. En ellos y en esta pregunta buscamos la afirmación de nuestra personalidad. Por supuesto, hemos tendido a valorar los comportamientos excepcionales, las «heroicidades», y a no darnos cuenta de que la "humilde cosa común» o las simples alegrías de los hechos comunes son los que componen la vida cotidiana; aunque tienen que estar realizados con un "poco de fe» que los anime, vivir con plenitud. Pero, probablemente, de eso, de sus propios límites, se dará cuenta don Quijote al final de su vida cuando es Alonso Quijano "el bueno» ${ }^{38}$.

${ }^{38}$ ELIAS CANETTI apunta: "Al espíritu que se ha acomodado no se le da crédito. Se da crédito a Holderlin, que pagó su espíritu con cuarenta años de locura» (Apuntes 1973-1984. Barcelona, Galaxia Gutenberg, 2000), p. 24. Casi cuatrocientos años antes también lo apuntó MONTAIGNE: «Si alguien preguntara a aquél [Alejandro] lo que sabe hacer, responderá: Subyugar al mundo; si se lo preguntan a éste [Sócrates], dirá: Vivir la vida humana conforme a su natural condición; ciencia mucho más general, de más peso y más legítima. El valor del alma no consiste en subir alto sino ordenadamente», ibid., III, p. 32. 